\title{
The GEMS Exams in Israel-Between Center and Periphery
}

\author{
Eli Ben Harus ${ }^{1} \&$ Nitza Davidovitch ${ }^{1}$ \\ ${ }^{1}$ Department of Education, Ariel University, Israel \\ Correspondence: Nitza Davidovitch, Department of Education, Ariel University, Israel.
}

Received: April 17, 2019

doi:10.5539/ies.v12n10p9

\author{
Accepted: July 18, 2019 Online Published: September 11, 2019 \\ URL: https://doi.org/10.5539/ies.v12n10p9
}

\begin{abstract}
The relationship between input and output is one of the leading topics in modern educational discourse. In the current study, we focus on the GEMS (Growth and Effectiveness Measures for Schools) exams in Israel, which constitute a measure of a school's scholastic achievements and its academic-social climate. The GEMS is the equivalent of exams such as the TIMSS and the PISA, used in other countries. The GEMS is a school supervisory tool of major importance operated by Israel's Ministry of Education for improving scholastic achievements and academic-social climate in schools. As an objective indicator, GEMS scores open the field of education to competition. Data on all schools in Israel whose students take the GEMS also appear on the National Authority for Measurement and Assessment in Education (RAMA) website. This study aims to examine the reasons for the disparities in the GEMS results between Israel's center and periphery and explores whether they can be reduced. Studies published on this issue in the last 16 years that explored these disparities, which are reflected in the extent of parental involvement and students' educational deficits, were conducted on behalf of RAMA and under its supervision, and some were not sufficiently critical in their review of the efficacy of the GEMS exams. Identifying and understanding these causes is a significant step toward reducing the disparities which have important implications for future acquisition of a secondary and tertiary education. The research findings offer a practical contribution for policy makers in the educational system, while identifying elements of positive change in the schools.
\end{abstract}

Keywords: effectiveness measures, GEMS exams, Israel, periphery

\section{Introduction}

The discourse in the educational world advocates the measurability of school norms and practices. At present, school climate is measured by means of climate questionnaires such as the GEMS (Growth and Effectiveness Measures for Schools), which is the main measurement tool administered by the Israeli Ministry of Education at all schools. The GEMS (in Hebrew - "Meitzav," a Hebrew acronym for Measures of School Efficacy and Growth) is an array of school measures used to assess scholastic achievements in science, English, math, and pupils' native language (Hebrew or Arabic). GEMS also includes an open-ended section in which students express their opinion about various aspects of their school associated with educational climate. The purpose of this section is to provide information to the principal and to the schools' pedagogical teams on the school's performance in a variety of areas. As a result, GEMS scores help schools monitor their scholastic process in core subjects as well as the emotional-social climate in which learning takes place.

Despite the great significance of measurable exams, there is increasing criticism of the efficacy of the GEMS. In 2018-2019, as GEMS attracted extensive media coverage and teachers' organizations threatened labor action if GEMS was not cancelled, the issue even reached the courts. The teachers' organizations instructed teachers at the schools to refrain from holding simulation exams or checking GEMS exams as part of the school's pedagogical arrangements. After a compromise was reached, it was agreed that the GEMS exams would be held but the scores would not be published as before but rather given to the school for its exclusive attention. In light of the above, it is very important to examine the GEMS exams and the disparities between the different districts.

In Israel, the disparities between the country's center and peripheries are reflected in numerous factors including less attractive places of employment, fewer schools with special curricula (such as schools for the arts or engineering) and more limited choice of schools and extra-curricular activities, as well as fewer advanced medical services. In the field of education, these disparities are associated with lower parental involvement, which leads to fewer tutoring sessions or assistance in learning of any kind, and absence of supplemental activities that enhance 
students' development. The absence of parental involvement in pedagogical issues may be reflected in a weaker parent association that is less involved in school activities and curricula. Furthermore, students in the peripheral regions often arrive at school with deficits that schools find difficult to overcome. As a result, these deficits accompany the children and are not resolved until they graduate. In central Israel, schools' goal is not to demonstrate good results on the GEMS but to achieve scholastic excellence and arouse students' curiosity for learning. In the peripheral regions, in contrast, schools invest effort to reach the national average scores on the GEMS.

In addition, as a junior high teacher working for over a decade in the periphery (southern district) the GEMS scores at my school intrigued me personally. From a wider perspective, it was evident that schools in southern Israel were showing no significant progress in the GEMS scores, in contrast to similar schools in central Israel that exhibited a constant rise in the scores, which were very high. According to a comparison of GEMS scores of schools in southern and central Israel, scores in core subjects (math, science, language, and English) range from 80 to 100 in central Israel and from 40 to 60 in schools in southern Israel, despite the smaller class size of schools in the southern district and the added study hours and tutoring that these schools are allotted, intended to reduce this disparity. Despite these efforts, no lasting change is observed, and the disparity between the two districts has remained nearly constant over the past decade. A comparison of GEMS scores in the central and northern districts shows a similar state of affairs. Schools in cities such as Safed, Tiberias, and Afula, consistently achieve scores that are low and below the national average. The current study focuses on a case study of GEMS scores in the southern district compared to the central district.

The purpose of the current study is to examine the source of the disparities in the GEMS scores between periphery and center, based on scholastic data presented on the RAMA website, which displays GEMS data for all schools in Israel. These data provide an accurate picture of the disparities in GEMS scores in these two districts in the period 2016-2019, with the aim of identifying the source of these differences.

In this article, we focus on the research literature on the use of measurement tests in schools around the world and in Israel and analyze what motivates the world to hold such exams and the influence of these measurements on education systems and resource distribution. We discuss the introduction of GEMS exams as part of the trend to promote measurement in education and how these measurements/ exams were introduced in Israel and policy makers' goals in introducing these tools in light of the global phenomenon of measurement. We analyze the problems stemming from measurement practices in Israel and attempt to explain how students' socioeconomic status might affect their achievements on exams in general and on the GEMS in particular. We describe how active parental involvement, associated with socioeconomic status, affects students' preparations for and results on the test. Finally, we address the objections and concerns of teachers and principals regarding the publication of GEMS data and the implications of such publications for the public.

\section{International Exams}

Use of international exams has greatly expanded since the 1990s, particularly under the influence of major organizations such as UNESCO, the World Bank, and the OECD. One of the main reasons for the increasing usage is the assumption that achievements on these exams predict future national economic growth, a premise that remains strong and significant among advocates of the exams, members of government in many developed countries, and educational policy makers in these countries. Those who hold to this premise presume to prove a direct linear relationship whereby each standard deviation in exam scores contributes one percentage point to the GDP per capita growth rate (Tamir, 2015).

Tamir (2015) offers a profusion of evidence and references proving the premise underlying the increased use of the exams. She relates how in 2001, then-director of PISA exams in the OECD, Schleicher, presented impressive graphs that allegedly indicated a clear impact of achievements on the exams on national economic growth. The World Bank too conveys a clear position by stating that a country's rank in exam scores will be taken into consideration by the bank when deciding on the level of aid to that country. In Israel, Ben-David stated that Israel's lack of success on the PISA exams constitutes an existential threat to the country and a socioeconomic time bomb (Tamir, 2015).

International exams such as the PISA and the TIMSS examine proficiency in fields that generate the knowledge required in a global world, such as math and science. The PISA assesses the literacy levels of 15-year-old students in reading, math, and science, and the extent to which students have acquired tools for thinking and comprehension in a manner that enables them to effectively cope with the challenges in their environment. The TIMSS examines students' command of math and science in the context of the curriculum. Israel embraced and standardized international exams, both in theory and in practice (Kliger, 2013). 
The major role of international exams on the educational agenda led to very significant changes in the strategic plan of education systems in certain countries - including changes in the distribution of resources, curricular changes, and changes in the nature of supervision over schools. In the early 2000 s, a significant change was initiated in the position on international exams versus internal research: Comparative research based on achievements on the international exams gradually attained more importance and significance than research in individual states, which began to be perceived as less relevant or significant (Porter \& Gamoran, 2002). Germany also changed significantly after the results of the PISA 2000, and the country was effectively no longer the same: Educational policy makers and citizens were shocked to discover that German students reached lower achievements than the general average of the OECD countries in which the exam was administered in the three areas measured by the exam - math, science, and language literacy. Consequently, policy designers introduced far-reaching changes in Germany's educational policy, manifested in establishing a new supervisory mechanism of educational standards, adapting the curriculum to the demands of the international exams, and adopting a general change in perception - from an inward-focused view to an outward-looking view that compares Germany with other countries (Ertl, 2006).

Finland was one of the top achievers in the PISA 2000. Finland's success on the exam, together with its flourishing economy, aroused much interest among many politicians and educational researchers from different countries, who tried to understand the secret of the Finnish success and how it could be emulated in local educational systems despite the social and demographic differences between Finland and their own country (Kregenbild, 2018).

A comprehensive analysis of attitudes to international exams in Israel and of the shifts that occurred in this field indicates that decision makers in Israel were attracted to the trend of comparing between developed countries, which they saw as an integral part of running a country in an era of globalization. Such comparisons were performed in numerous areas and employed a range of parameters. In education, comparisons were based on a variety of international exams that focused mainly on scientific knowledge, mathematical reasoning, and language literacy. Indeed, over the past two decades the heads of the educational system devoted much time and resources to improving Israel's ranking in the international exams. The methods used by the heads of the educational system to ensure proper preparation for the exams included an efficient distribution of resources, suitable study programs, and stricter supervision of the schools. For example, since Limor Livnat's appointment as Minister of Education, and following the publication of achievements on the PISA 2000 (Israeli students took the exam in 2000), the Ministry's policy changed considerably — from a policy that emphasized teachers' empowerment and school autonomy in the late 1990s, to a policy of setting standards for and constantly examining academic achievements through an intricate system of supervision and control. In 2004, the National Task Force for the Advancement of Education in Israel was established, headed by entrepreneur Dovrat. The Dovrat Committee, as the task force became known, mainly addressed structural changes in the educational system, and one of its declarations was that "by the end of the current decade Israel will be among the top countries in the OECD on international achievement exams" (Yogev, Livne, \& Feniger, 2009, p. 334).

The significance attributed by the Ministry of Education (2009) to achievements in the international exams is evident from the work plan of the Director General for 2009-2012: In the long run, Israel would be one of the world's ten leading countries in international achievements, and in four years it would reach the world average in the international exams. In two years, the education system would advance two places in the international rankings for 8th grade (TIMSS), in the exam to be held in math and science in 2011. In three years, Israel's educational system would advance five places in the international ranking in math and 10 places in science in the PISA exam to be held in 2012. In two years, students' achievements on the GEMS would improve by $10 \%$. These goals, aimed at bringing about an improvement in students' achievements and a rise in international rankings, require operative steps that have already been initiated, such as increasing the number of hours dedicated to teaching science in junior high schools and developing structured teaching units that include scientific and pedagogic background material for teachers, among others assessment items on high levels of reasoning. Also evident is the system's perception of international exams and of the commitment to students and their parents to do everything possible to render the matriculation certificate uniform, prestigious, high quality, and up to international standards, as embraced by leading countries such as OECD countries.

The Ministry of Education developed literacy tasks as part of the program to cultivate literacy in all subjects examined in the PISA exam, and questions in this spirit were introduced into the matriculation exams, as noted below. The program for cultivating literacy was adapted both to the curricula in each field and to international standards as defined by the OECD. Although these topics appear in the curricula, insufficient emphasis appears to have been given in the past to the topic of literacy. This means verbal, integrative, authentic assignments that demand the ability to implement knowledge. These topics will find expression in the matriculation exams (Kliger, 
2013).

\section{The GEMS Exams-The Development of Israeli Standards}

The desire to use exams that meet international standards led Israel to adopt the GEMS (Growth and Effectiveness Measures for Schools), exams intended to measure a school's scholastic achievements and academic-social climate. The GEMS is the only tool that provides an objective picture of the school. The GEMS exams have been used for about 16 years. The GEMS is administered once every two years as an internal exam by the school staff, and two years later it is administered again by the Ministry of Education as an external exam. They were first introduced in 2002 as an external measure for elementary school and junior high school achievements, allowing comparisons among schools, and comparisons with the requirements of the Ministry of Education in the subjects of Hebrew/Arabic, science, English, and math. The results of the exams are intended to help school principals and teachers monitor academic progress, determine school goals, and allocate resources such as extra hours and budgets (Cahan, 2008).

In light of the Dovrat Committee Report (2005) and its recommendations, in 2006 the Ministry of Education decided on a reevaluation of the external GEMS exam, which would henceforth be administered once every four years. The Dovrat Report sees the GEMS as a mirror of the school for the community of parents, and also places full responsibility on the teachers who prepare their students for the exam itself. The Dovrat Report was the first to speak about publicizing the scores received on the GEMS to the community of parents instead of the previous situation, in which test scores were revealed only to the Ministry of Education.

\subsection{Advantages of the GEMS Exams}

Parents complained that they were not receiving the relevant information concerning their children's GEMS scores, and worse, that this information was being concealed from them. In the popular online newspaper Ynet, Melamed (2013) protested against the education system's conduct regarding the GEMS, one of RAMA's 'top exams'. According to Melamed, the previous Minister of Education believed Israel's citizens did not deserve to receive information on the performance of students from different local municipalities. Melamed stated that educational funds provided by the municipalities are covered by municipal taxes and therefore, parents deserve to know how their children are doing in school.

\subsubsection{Objectivity}

In its current form, GEMS provides an objective picture of the schools, and as a result, schools can plan how and where they must improve. Zohar (2013) sees the GEMS as a potential tool for supervising principals and staff when results are not positive. Teachers preparing their classes for the GEMS do not operate in a void but rather in a complex organizational system. Both the school supervisor and the school principal strive to promote achievement-oriented excellence in all study subjects, but particularly in those in which external exams are held, which have a more significant impact on the school's image. Achievement-oriented success in these subjects is a measure of the proper functioning of the supervisor and the principal, as well as the functioning of the teachers (Justman \& Bukobza, 2009).

\subsubsection{Platform for Improving and Upgrading the School}

Open dialogue empowers teachers, shapes them as professionals, enables them to critically observe the teaching context (Avidar, 2006), and allows them to use the tools they acquired to cope with the circumstances. In western society, parents and stakeholders demand to know more about what is happening in the system (Fresko, Wertheim, \& Lazovsky, 2011) and they demand transparent learning and teaching processes when these involve their children. Open dialogue between the system and the schools will serve both the parents and the stakeholders and generate the desired change - an improvement in teaching and heightened accountability.

Others advocate other methods to evaluate school achievements. Berliner (2005) claims that in order to significantly and truly improve a school's achievements, it is necessary to arrange for intensive learning and daily practice rather than a specific annual solution when the GEMS is held. Namely, in his opinion, diverting resources and holding 'marathons' prior to the GEMS might improve the school's measures on specific scores but does not attest to a significant, fundamental change within the school. Some of the problems raised by Feniger (2010) were solved over the years by introducing more stringent rules for administering the GEMS, such as the requirement that over $80 \%$ of the students must complete the exam, to prevent the exclusion of poorly functioning students (Feniger, 2010).

Harpaz (2007) explains that external GEMS or external matriculation exams alone are an inadequate measure of school achievements, and the combination of these two types of evaluations will give the school a comprehensive picture. Any form of evaluation that is based on a single numerical raw score cannot accurately reflect the school's 
achievements and transforms the discourse into one that is merely technical. Assessment is a complex process that requires attention to different points of view with regard to what is happening at the school. External evaluation gives schools an opportunity to confront the findings, under the assumption that this confrontation will bring with it good things for the school.

\subsection{Drawbacks of the GEMS}

Keeping students away on the day of the exam, extracting poorly functioning students from classrooms when administering the GEMS, helping students during the exam, and correcting students' answers on the exam by teachers and principals, are some of the methods utilized at some schools in order to maintain high scores regarding the school's level of knowledge and climate.

\subsubsection{Trustworthiness}

Ravitch (2010) refers to the problem of data trustworthiness in high-stake exams. Ravitch was originally in favor of high-stake exams and appreciates their contribution to improving schools. She supported the transformation of schools into business organizations and even introduced practices customary in modern high performance organizations. Over time, she understood the damage that such exams cause to the education system. She says that examinations have become a major occupation in schools, have ceased to function as a measure, and have become a goal unto itself. Accountability, as she sees it, is causing countries and educational districts to strive for unrealistic goals and is not raising standards.

The principle of accountability mentioned by Ravitch (2010) began with the US economic conception that called for measurement of the ratio between investments in education and outputs using a set of indicators developed for this purpose; Israel was of course affected by this policy as well (Dahan \& Yona, 2006; Friedman \& Philosoph, 2001). Some of the concepts included in the principle of accountability refer to decentralization, opening school zones, parental choice, privatization, applying competitive mechanisms, and self-management, including external supervision (Hopmann, 2008; Kliger, 2009; Volansky, 1999). Ravitch (2010) further claims that external supervision gives the school or the student a final score and compares students across districts, which raises students' chances of success in the transition from high school to academic studies.

The study conducted by Hunt et al. (2009) stresses the pressure applied to the teachers who administer the evaluation exams and the sad reality of changes in study methods adopted in order to help students pass the exams. The study was conducted in the state of Illinois, US, and it was based on interviews with 42 teachers and six principals from an area with a large population with low socioeconomic status and minorities. The results show that the teachers admitted that they changed the study methods they use in order to allow their students to practice questions resembling those on the examination and they even changed the curriculum in order to devote more hours for teaching the subjects in the examination and more time to the material taught for the examination. The teachers stated that the changes stem from pressure of the potential implications if their students were to fail the examination (Hunt et al., 2009).

\subsubsection{Resource Diversion}

Resource diversion is a massive re-organization prior to the exam aimed at improving the school's measures, including 'marathons' and diverting resources to the classes where students will be taking the GEMS (Harpaz, 2007). The research literature provides evidence of such resource diversion in Israel. Bustanai-Halfon (2016) found that principals divert resources when holding the external GEMS versus the internal GEMS. In addition, schools function differently in the years when the external GEMS is held. The GEMS exams, considered system-wide high-stake exams, involve significant rewards and penalties for the teachers. The system awards positive rewards for high achievements on the exams, such as added wages or bonuses for teachers, and negative rewards for low achievements, such as sanctions, reprimands, publicizing poor achievements in the media, dismissal of principal or teachers, and even closure of schools. Experience shows that an exam can become a high-stake exam even in the absence of administrative sanctions: Pressure on teachers is sufficient to affect their teaching (Zohar, 2013).

Evidence also shows that school managements allocate institutional resources for assessment by standard external exams at the expense of academic and educational operations not measured by these exams (Beller, 2011). In the educational system, some critics expect this phenomenon to increase following the court ruling requiring the publication of school achievements on standard exams (Feniger, 2010).

Another example of massive disproportionate arrangements is evident from analysis of documents accompanying the science and technology curriculum. HELA kits (Hebrew acronym for teaching-learning-evaluation) are an example of how what to teach, how to teach, and how to evaluate students is dictated from above. The main 
document defines a strict schedule and clear outputs for teachers. This involves considerable centralization overseen by the supervision, constant control, applying a great deal of pressure on the teachers to produce the necessary outcomes and raise students' achievements on the exams. The official policy of the Ministry of Education is that these exams require no preparation, but in practice, the entire educational system is occupied by preparations for the exams. Tzameret, director of the pedagogic secretariat in the Ministry of Education, says that great emphasis is put on the scores and on the examinations. Schools stop all studies about one month before the GEMS and focus on the GEMS. Instead of study programs and pedagogy being the primary goal of education, which the exams assess, passing the exams has become the goal (Kliger, 2013).

Despite the official approach of the Ministry of Education that students should not have to prepare for international exams and national exams, in 2003 schools prepared for the TIMSS exam through various measures including development of study materials in quantitative reasoning, continued education of teachers in math, and allocation of special hours for math in 8th grade (Zaslavsky, 2006). In addition, the students received explanations about the exam's significance and how to perform well on the exam (Beller, 2011).

Pressure by various educational authorities might compromise the integrity of the GEMS exams (Crooks, 2006). For example, principals try to maximize scores by diverting resources in the year the GEMS is held, and refrain from investing resources to build a growth-generating pedagogical program for the school (Zohar, 2013). In addition, there are disparities in the GEMS scores between selective and non-selective schools (Ben Harush, 2016) and the exams' efficacy is questionable (Feniger, 2010). Principals might gather the staff at the beginning the year and explain the significance of preparation for the GEMS, while emphasizing the importance of practice and subject-focused days during the year. Teachers assigned to GEMS classrooms are experts in the specific discipline with much experience in administering the GEMS. In recent years (Bustanai-Halfon, 2016) teachers are sometimes also asked to confirm whether they need special resources in the year of the examination, and they are informed of the significance of passing the exam.

In his study, Gilboa (2010) examined whether the education system reduces the disparities in scholastic achievements among Jewish children aged 10-14 in the government educational system, who come from different socioeconomic backgrounds. He says that the GEMS examinations, which some students take more than once over their years of schooling, make it possible to identify educational lacunae at an early stage of schooling when it is still possible to reduce the disparities in achievements, at least to some degree, but schools are only partially successful in reducing these disparities. The findings of this study show that students' family background continues to constitute a significant factor in determining scholastic achievements and that schools only partially succeed in compensating students with weaker backgrounds. In math, the disparities between scores are increasing, while in Hebrew they are on the decline. School-level scores show considerable differences between the achievements of students from schools with different levels of academic support. The likelihood that they will improve their grades from $5^{\text {th }}$ to $8^{\text {th }}$ grade is also higher.

Gilboa (2010) notes that disparities in math scores are growing. While disparities in Hebrew are indeed declining, it is not clear whether this tendency will continue in more advanced years in school or disappear by the end of high school. The results of the matriculation exams show that differential budgeting is used to allocate resources to schools with the aim of reducing disparities in the achievements of students from various socioeconomic backgrounds. Assuming that schools utilize their budget efficiently, the only way of improving the achievements is to increase school budgets so that school can invest additional resources in helping low-achieving students. As a result, students' achievements should be factored into the school budgeting formula. However, adding the student's achievements to the index is not a simple feat, and involves a moral hazard: Since a school's budget is reduced when its students show higher achievements, the school has a stake in refraining from nurturing low-achieving students to prevent cuts in its budget. In contrast, Gilboa (2010) recommends a dynamic academic support index that is updated periodically based on students' achievements, which will lead to better allocation of resources and increase students' achievements in Israel.

\section{Ethics}

The public tends to see the GEMS exams as a simple matter: The exam is administered and then a numerical score is calculated. Koretz (2008) cautions that it is very easy to err by asking overly general questions or ignoring the complex elements that factor into a school's results, or interpret the data in a manner that is intended to project a specific image of a school. As a result of these possibilities, it is difficult to state that the ethics aspects of the exams are being upheld. Admittedly, it is very difficult to quantify a school's overall complexity in a numerical score that reflects all aspects of a school's achievements and standards. Of course, the limited number of questions in these exams constitutes a representative sample that cannot give us a comprehensive picture of the school's 
standards. Koretz (2008) further defines the fraud problem as grade inflation, which is an artificial rise in grades that does not reflect a real increase in knowledge in the field measured by the exam. He explains principals' wish to demonstrate that the exams are effective and positive by showing that test scores increase annually in their schools, and to show that the exam identifies problem areas that the principals are addressing. However, when a new exam is introduced to measure schools, a sharp drop in achievements is evident, and is followed by a steady rise in achievements over the next several years (Koretz, 2008).

\section{Publicizing}

Publicizing the results of standard exams held in the US has a direct effect on the school's existence. The success or lack of success of certain students, specific teachers, or the entire school on the examination leads to systemic intervention. For students, lack of success on the examination might lead to forced dropout, keeping a student back, or other sanctions applied to the child personally. For teachers, sanctions may be applied to the teacher when many students of a certain teacher do not pass the examination, such as placement in certain classes with a low chance of student success, preventing promotion, and even dismissal. In contrast, a teacher's success can lead to a one-time or regular monetary bonus and to promotion. For schools, the consequences of success and failure range from awarding funds to outstanding schools for the purpose of supporting disadvantaged students, to the closure of failing schools (Darling-Hammond, 2007; Yair \& Inbar, 2006).

Publicizing GEMS data exposes schools that do not meet the GEMS goals to criticism and may even lead to the dismissal of their teachers or principals. In the education system, this phenomenon is expected to increase in light of the court ruling that requires public advertising of school achievements on standard exams (Feniger, 2010). Nevertheless, there are still differences in attitudes to standard exam results in the US and the GEMS exams in Israel. An American school that does not meet its annual goals might be closed or its management will be changed. The incentive to cheat in this case is significant. In Israel, in contrast, the GEMS exams have no direct consequences for students, teachers, or school management, although many educators and educational administrators have voiced objections to the publication of the results (Berliner, 2005).

The purpose of the GEMS examinations held in Israel, is to measure comprehension and knowledge and to rank the schools. These examinations have little impact on students or teachers. Schools receive scores by class and not by child, and therefore it is not possible to provide reinforcement to certain children or to assess the abilities of each child individually. While it is possible to reach conclusions about the quality of individual teachers' teaching based on the results of the exams, this information is not utilized and teachers are not affected by their students' test scores. The feedback given to the schools refers to the school as a whole rather than to individual teachers. The exams have an impact on schools, but this is manifested mainly in decisions to provide assistance to weaker schools in order to strengthen them based on the rankings.

Some principles object to publicizing the GEMS results. In a large study that included 1,144 principals, 863 in Hebrew speaking schools and 281 in Arabic speaking schools, who constitute a representative sample of elementary and junior high school principals (Ministry of Education RAMA, 2014), principals' views on publicizing the GEMS data were divided. A considerable proportion of the principals believed that publicizing the scores would have no effect on schools in general while a significant proportion of the principals believed that publication of the scores would have either a positive or a negative effect on schools. Principals' answers were divided mainly by language sector: principals of Arabic speaking schools tended to attribute positive effects to publication of scores (effects on the students, on the schools' relationship with parents, and on the school in general), while most of the Hebrew speaking principals thought that publicizing the scores has no effect in the various spheres. The remaining principals were divided between those who thought that publicizing would have a positive effect and those who thought that it would have a negative effect (Nasser-Abu, 2007).

In contrast, regarding the effect of test scores' publication on the teachers, the majority of principals of Hebrew speaking elementary schools thought that publicizing would have a negative effect on them. It was also possible to understand from the data that, in general, principals in high-achieving schools were inclined to attribute positive effects to publicizing (and of course vice versa: the lower the school's achievements, the greater the inclination to attribute negative effects to publicizing). The justifications raised by principals who thought that publicizing has a positive effect were based mainly on the belief that publicizing would generate healthy competition (between the schools, between the teachers, etc.) and that this would lead to overall improvement within the system. Many of the voices that attributed positive effects to publicizing proved their conception by citing their own school's success (with regard to achievement measures, climate measures, etc.), which they wished to publicize. Principals who objected to publicizing justified their views by saying that publicizing would harm efforts to enhance the school's uniqueness by creating excessive competition between the schools and creating pressure on teachers; and because 
exam scores, positive as they may be, reflect only part of the school's work and of the disciplines taught but are interpreted by the public as the only and absolute indices for evaluating schools (Ministry of Education RAMA, 2014).

The issue of publicizing the GEMS data is continuing to spark debates among educators. In early 2019, after a widely covered disagreement in the media between the Ministry of Education and the teachers' organizations on the issue of holding the GEMS exams, the labor courts ruled in favor of the teachers' organizations and ordered that the results of the GEMS should not be publicized but demanded that the exams be administered as the Ministry of Education demanded. The Ministry is making efforts to find an exam to replace the GEMS, but it is clear to everyone that this new exam will be an objective national exam that will measure school achievements and even stop making the results public (Dattel, 2019).

\section{Socioeconomic Status and Parent Involvement}

One of the most significant factors affecting students' success in life in general and academic success in particular is the socioeconomic status of their families of origin. A strong relationship was found between demographic characteristics and achievements, more than between ethnic origins and achievements. Socioeconomic status is a complex demographic variable that normally includes the parents' education and occupations, household income, and family structure (Levendecker, Harwood, Comparini, \& Yalcinkaya, 2005). It has been found to be related to a variety of human outcomes and behaviors, such as overall health, infant mortality rate (Adler et al., 1994), cardiopulmonary diseases, mental illnesses (schizophrenia and depression), obesity (Beydoun \& Wang, 2009), and others. Studies have also found a relationship between sociodemographic status and variables related to parenting style. Socioeconomic status was found to be related to parents' basic beliefs concerning parenting and long-term goals of socialization (Duncan, Young, Brooks-Gunn \& Smith, 1998). For example, low socioeconomic status was found related to a belief in dictatorial principles and greater use of punishments. This finding was explained by the higher appreciation for conformism and obedience among parents from lower socioeconomic status who consequently expect such conduct from their children (Hoff-Ginsberg \& Tardif, 1995).

Hoff-Ginsberg and Tardif (1995) found a correlation between socioeconomic status (calculated as a continuous variable by the education of both parents and the father's occupation) and the mother's expectations concerning her children's development in Japanese and American samples. Mothers with a higher socioeconomic status expected their children to achieve school-related skills at a younger age. They also found that, in Japan, mothers with a higher socioeconomic status expected their children to achieve social skills at a younger age. In contrast, US mothers with a higher socioeconomic status expected verbal assertiveness at a younger age. This finding indicates an association between the type of expectations and the main values in one's culture. Many studies have indicated a general pattern whereby parents with low socioeconomic status emphasize values of conformism, while parents with a higher socioeconomic status emphasize values of independence (Hoff-Ginsberg \& Tardif, 1995).

Contemporary approaches posit that it is necessary to examine the effect of the factors that comprise the socioeconomic status index separately. For example, parents' education, and particularly that of the mother, constitutes the main factor that affects knowledge of parenting, parental beliefs and practices (Bornstein, Hahn, \& Suwalsky, 2013; Bornstein, Hahn, Suwalsky, \& Haynes, 2003; Levendecker et al., 2005). In addition, consistent parent involvement was found to be positively related to children's academic performance. Policy makers adapt their funding efforts according to these findings, with the aim of increasing parent involvement through wider political and educational initiatives, since a stable home with stable parents have an impact on early academic success (Hill \& Craft, 2003).

Petit, Bates and Dodge (1997) also describe how good relations with one's parents in childhood, continuing in adolescence, have a positive effect on children's learning. The more involved and significant the parents are in their children's lives, the more they manage to provide them with a high sense of academic efficacy and capacity to pass exams. When investigating success in undergraduate studies, Davidovitch (2005) also found a relationship between students' personal and family characteristics (including education and socioeconomic status) and their self-efficacy (which is a strong predictor of undergraduate academic success). The most significant family variables contributing to self-efficacy were found to be the father's education, the mother's education, and evaluation of the parent's financial status.

In another study that examined the policy regarding access to undergraduate studies in Israel, with a focus on populations in the periphery versus the center, Davidovitch (2015) concluded that the accessibility policy regarding undergraduate studies has proven itself. From 1990 to 2012, the number of students from all regions rose but the proportion of students from southern Israel rose from $10 \%$ to $15 \%$, the proportion of students from northern Israel rose from 0 to $10 \%$, and from central Israel (outside the three large cities) from $4 \%$ to $5.17 \%$.. However, 
there is a disparity between periphery and center in the quality of the degrees earned, by virtue of the fact that the degrees earned in institutions opened in the periphery are college degrees, where admission terms are more lax and 'softer' disciplines are taught (Davidovitch, 2015).

\section{Efficacy of the GEMS Exams-Summary and Conclusion}

Research findings over the years highlight the question of the GEMS exams' efficacy. The different opinions of two educators, Cahan and Zohar, illustrate the debate over efficacy. Cahan (2008) thinks that the exam should include all students in each school, in all classes, in all disciplines, at least once a year - an untenable suggestion as it disregards the damage that might be inflicted upon the schools due to such an intensive system of exams. Systemic exams have negative aspects as well: since it is not possible to test all aims of a study program, and it is of course not possible to examine all educational-social goals of a school, the exams will lead to an emphasis on goals that are easily assessable and to the neglect of other important goals (academic, social, and ethical). Furthermore, high-stake exams have the effect of discriminating against weaker populations, diminishing intrinsic motivation to learn, creating a climate of tension and anxiety, and increasing various types of cheating.

Zohar (2013), in contrast, supports the significance of the GEMS exam findings and argues that the main designation of the GEMS is to serve as an assessment tool for school principals for the purpose of improving teaching and learning. The GEMS is supposed to provide school principals with more trustworthy data than they can receive from exams composed by school teachers. It should not be used by the system as a tool to supervise schools. Responding to Cahan's claim, Zohar notes that this is the reason that the educational system seeks the 'golden path': to glean important information from the exams on one hand while minimizing potential harm stemming from excessive test-taking on the other. The result of such thinking is the GEMS exam in its present format. In contrast to Cahan, Zohar does not think that the grades should be comparable between class levels and disciplines - such a comparison is not a goal of the exams. If the exams are reliable and calibrated, the system can generate important information even without such comparisons. The internal GEMS gives school principals important evaluation tools and promotes a culture of evaluation within the school, while the external GEMS provides information on the achievements relative to the national norm (Zohar, 2013). Hence, the efficacy of the GEMS exams is not clear, but lacking any other measurement tool, the Ministry of Education has decided to use the GEMS as the major measurement tool for examining the school's level.

The research literature indicates the need to formulate a model with the purpose of examining the factors affecting scholastic achievements - with reference to the school's geography. The current case study relates to the GEMS exams.

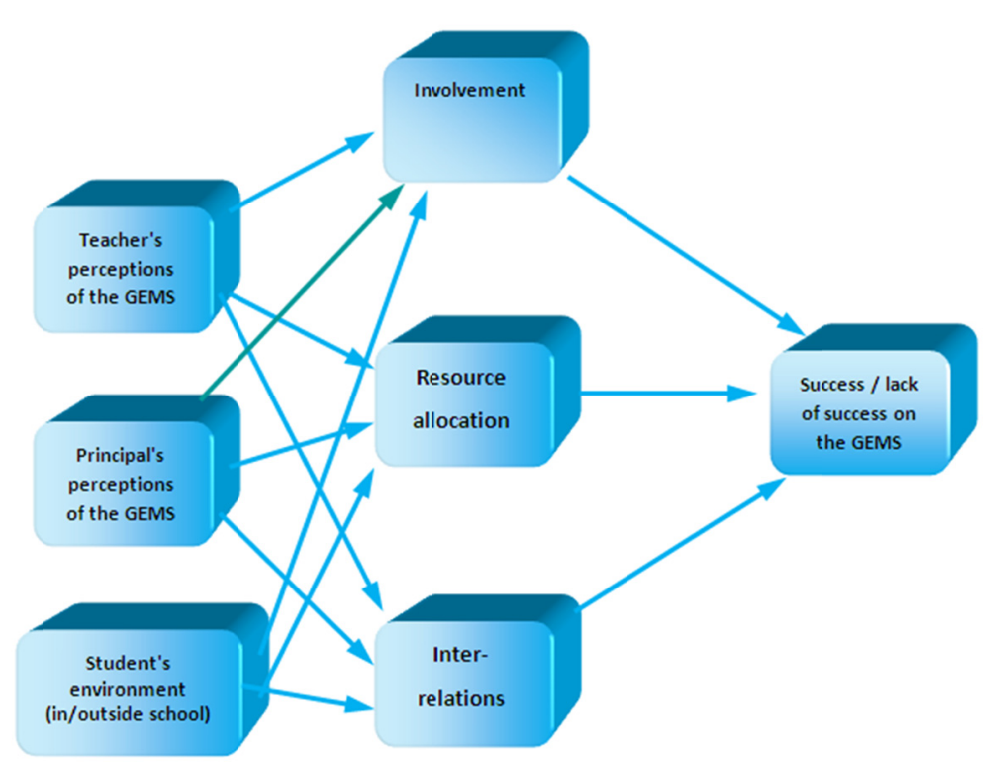

Figure 1. Proposed model of success on GEMS

The theoretical model shows that individual success/lack of success on the GEMS is based on the interactions 
among several variables: the teacher's perception of the GEMS, the principal's perception of the GEMS, and the student's environment.

The teacher's perception of the GEMS includes: helping the student advance by checking homework and through reinforcement and focus classes; demonstrating restraint concerning disciplinary problems, tardiness, and absences while studying for the GEMS; directing the teacher's personal involvement in his work; extent of work put into preparing instruction of the subject; extent of work put into preparing the lessons and their implementation. The principal's perception of the GEMS includes: personal interest in developments concerning instruction of the subject; discourse with the teaching staff on subject-specific topics in the examination; frequent meetings toward the examination emphasizing the goal of raising students' achievements; understanding that the students' achievements might affect the school principal's attitude to the teacher as well as allocation of resources to the studied subject. The student's environment in the school and outside it: informing the parents of the student's achievement level, directing the parents, and enlisting their help with the student toward the examination.

The contribution of the theoretical framework arising from the research literature is in formulating a model that refers to the dimensions affecting scholastic achievements from a geographical perspective. The current case study of the GEMS exams might constitute a model for examining other achievements in light of the fact that geographic aspects have socioeconomic significance.

The significance of the current study derives from the lack of accumulated knowledge in Israel concerning climate tests such as the GEMS and high-stake exams, versus the large number of studies and accumulated knowledge on climate tests and high-stake exams around the world, such as the PISA. The PISA (Programme for International Student Assessment) is a major comparison exam. It is administered once every three years and checks students' achievements at age 15 in the subjects of math, science, and language literacy (Pollack, 2012). The experience accumulated in 20 years of high-stake systemic exams in the US and in other countries makes it possible to examine their impact over time.

Administration of these exams elicits strong criticism from different directions (Koretz, 2008; Ravitch, 2010). The common criticism at present is that even if the principle of accountability is a positive one, it still causes harm to the educational system. An increasing number of educators have concluded that accountability is dangerous and harmful (Zohar, 2013). While educational systems around the world have indeed administered systemic exams despite the criticism from many quarters, in Israel no extensive public debate has been conducted to date on the significance of administering such exams. The lack of knowledge about systemic exams in Israel such as the GEMS exams, and the desire to introduce in Israel a policy that has already proven problematic, requires us to stop, think, and thoroughly study the lessons learned in other places, and only then to reach an informed, well-grounded decision (Zohar, 2013). The current study aims to address this need.

Recently, there is a trend in Israel of gathering information on climate tests and checking their effectiveness. On one hand, there is room for additional research based on the data gathered annually in Israel, in order to promote specific knowledge in the field and in order to improve the school climate and students' scholastic achievements. On the other, a study should be held to examine the source of the disparate scores achieved by Israel's different regions. Close inspection of the data for a boys' high school in southern Israel (Ben Harush, 2016) shows that all GEMS grades in 2016 were lower than the national average (for example, an average of 49 versus a national average of 60 in math; an average of 60 versus a national average of 74 in English). In contrast, the data for a boys' high school in central Israel indicates that all GEMS grades in 2016 were higher than the national average (for example: an average of 72 versus the national average of 60 in math; an average of 88 versus the national average of 74 in English). It is evident that the GEMS grades in the southern school were lower than the national average while the GEMS grades in the central school were above the national average by several percentage points. These findings should be studied further. In summary, this study illuminates an issue of social, educational, sociological, and psychological significance, related to scholastic achievements from an interdisciplinary perspective, with the motivating factor being geographic location.

\section{References}

Adler, N. E., Boyce, T., Chesney, M. A., Cohen, S., Folkman, S., Kahn, R. L., \& Syme, S. L. (1994). Socioeconomic status and health. The challenge of the gradient. American Psychology, 49, 15-24. https://doi.org/10.1037/0003-066X.49.1.15

Avidar, S. (2006). Assessment and bias factors. Dapim, 41, 10-37. [Hebrew]

Beller, M. (2010). Measurement in the service of learning: Theory and practice. Jerusalem: Ministry of Education. 
Beller, M. (2011). Israel's participation in the international studies, what is examined, when is it examined, and why is it worthwhile? Retrieved from http://cms.education.gov.il/EducationCMS/Units/Rama/Mivchanim BenLeumiyim/MS_TIMSS_2011.htm

Ben Harush, A. (2016). The disparity between student and teacher reports regarding school climate in junior highs in the state religious educational system: An interpretive view of gender and selectivity (MA thesis, Department of Education, Ben Gurion University).

Berliner, D. C. (2005). Our impoverished view of educational reform. Teachers College Record. https://doi.org/10.1111/j.1467-9620.2006.00682.x

Beydoun, M. A., \& Wang, Y. (2009). Pathways linking socioeconomic status to obesity through depression and lifestyle factors among young US adults. Journal of Affective Disorders, 123, 52-63. https://doi.org/10.1016/j.jad.2009.09.021

Bornstein, M. H., Hahn, C. S., Suwalsky, J. T. D., \& Haynes, O. M. (2003). Socioeconomic status, parenting and child development: The Hollingshead Four-Factor Index of Social Status and the Socioeconomic Index of Occupations. In M. H. Bornstein, \& R. H. Bradley (Eds.), Socioeconomic status, parenting, and child development (pp. 29-82). Mahwah, NJ: Erlbaum.

Bornstein, M. H., Hahn, C.-S., \& Suwalsky, J. T. (2013). Physically developed and exploratory young infants contribute to their own long-term academic achievement. Psychological Science, 24(10), 1906-1917. https://doi.org/10.1177/0956797613479974

Bustanai-Halfon, A. (2016). Differences of school performance according to years in which internal and external standard tests are performed (Master's thesis, Bar-Ilan University, Ramat Gan).

Cahan, S. (2008). Use of educational indicators for setting policy and making decisions: Achievement exams in the GEMS. Invited review as background for the work of the committee on indicators for the educational system. School of Education, Hebrew University of Jerusalem, Israel.

Crooks T. J. (2006). Excellence in assessment for accountability purposes. Keynote address presented at the North Umbria EARLI SIG Assessment Conference (Newcastle, UK, August 31).

Dahan, Y., \& Yona, Y. (2006). The Dovrat Report, equality of opportunity, and Israeli reality. Teorya Uvikoret, 28, 101-125.

Darling-Hammond, L. (2007). Race, inequality and educational accountability: The irony of 'No child left behind'. Race Ethnicity and Education, 10, 245-260. https://doi.org/10.1080/13613320701503207

Dattel, L. (2019, February 7). The GEMS scandal: The labor court approved the labor dispute of the Teachers' Association. TheMarker. Retrieved from https://www.themarker.com/news/education/1.6915869

Davidovitch, N. (2005). Higher education at a crossroads: Trends in the development of regional colleges and their implications for higher education system in Israel. Bar-Ilan University.

Davidovitch, N. (2015). Accessibility of higher education in Israel: The dream and its collapse. In I. Basok (Ed.), Education and employment: An inseparable pair? - On education and schooling as an introduction to a working life (pp. 7-15). Department of Publications, Ministry of Education.

Dovrat Committee Report. (2005). Retrieved from https://www.makorrishon.co.il/nrg/images/stuff/news/Dovrat_ 05.01.05.pdf

Duncan, G. J., Yeung, W. J., Brooks-Gunn, J., \& Smith, J. R. (1998). How much does childhood poverty affect the life chances of children? American Sociological Review, 63, 406-423. https://doi.org/10.2307/2657556

Ertl, H. (2006). Educational standards and the changing discourse on education: The reception and consequences of the PISA study in Germany. Oxford Review of Education, 32(5), 619-634. https://doi.org/10.1080/03054980600976320

Feniger, Y. (2010). Are the Meitzav exams good or bad for our educational system? Hed Hachinuch El Hame'ah Ha-21, 84(4), 22-27. Retrieved from http://portal.macam.ac.il/ArticlePage.aspx?id=2995

Fresko, B., Wertheim, C., \& Lazovsky, R. (Eds.) (2011). Evaluation as a guide for action. Tel Aviv: Mofet Institute.

Friedman, I., \& Philosoph, S. (2001). Standards in education. Jerusalem: Szold Institute.

Gilboa, Y. (2010). Are the gaps in education growing smaller? Policy study 10. Jerusalem: Van Leer Institute. 
Harpaz, Y. (2007). Accountability means shirking responsibility. Hed Hachinuch El Hame'ah Ha-21, 81(7), 24-27.

Hill, N. E., \& Craft, S. A. (2003). Parent school involvement and school performance: Mediated pathways among socioeconomically comparable African-American and Euro-American families. Journal of Educational Psychology, 95, 74-83. https://doi.org/10.1037/0022-0663.95.1.74

Hoff-Ginsberg, E., \& Tardif, T. (1995). Socioeconomic status and parenting. In M. H. Bornstein (Ed.), Handbook of parenting: Vol. 2: Biology and ecology (pp. 161-199). Hillsdale, NJ: Erlbaum.

Hopmann, S. T. (2008). No child, no school, no state left behind: Schooling in the age of accountability. Journal of Curriculum Studies, 40, 417-457. https://doi.org/10.1080/00220270801989818

Hunt, J. W., Afolayan, M., Byrd-Blake, M., Fabunmi, M., Pryor, B., \& Aboro, P. (2009). The impact of the pressures to make adequate yearly progress on teachers in a midwest urban school district: A qualitative analysis. Journal of Public Economics, 89, 761-796. https://doi.org/10.2307/jthought.44.3-4.63

Justman, M., \& Bukobza, G. (2009). Guidelines for revising the system of education indicators in Israel. Israel Academy of Sciences and Humanities, Jerusalem.

Kliger, A. (2009). Between the GEMS and the situation: Principals perceive and teach the goals of the GEMS as opposed to the declared goals. Dapim, 47, 142-184.

Kliger, A. (2013). International exams as the standard in the education system. Maof U'Ma'aseh, 15, 97-108.

Koretz, D. (2008). Measuring up: What educational testing really tells us. Cambridge, MA: Harvard University Press.

Kregenbild, T. (2018). The educational system-Part 6: The secret weapon of Finland's educational system. Easyconomy. Retrieved from https://easyconomy.com/\%D7\%97\%D7\%9C\%D7\%A7-\%D7\%95-0D7\%9E\% D7\%A2\%D7\%A8\%D7\%9B\%D7\%AA- \%D7\%94\%D7\%97\%D7\%99\%D7\%A0\%D7\%95\%D7\%9A- \%D7\% A9\%D7\%9C-\%D7\%A4\%D7\%99\%D7\%A0\%D7\%9C\%D7\%A0\%D7\%93

Leyendecker, B., Harwood, R. L., Comparini, L., \& Yalcinkaya, A. (2005). Socioeconomic status, ethnicity, and parenting. In T. Luster, \& L. Okagaki, (Eds.), Parenting: An ecological perspective (pp. 319-342). Hillsdale, NJ: Erlbaum.

Melamed, A. (28 May, 2013). So that we shall not know: Concealed to keep us quiet. http://www.ynet.co.il/:ynet,articles/0,7340,L-4385075,00.htm

Ministry of Education. (2009). Aims and goals of the ministry for the years 2009-2012. Retrieved from http://www.schooly2.co.il/oranit/page.asp?page_parent=10126:2011

Ministry of Education RAMA. (2014). Attitudes of principals toward the Meitzav and its publicizing. Survey of principals in the Meitzav 2013.

Nasser-Abu, F. (2007). Mass assessment: risks and opportunities. Hed Hachinuch El Hame'ah Ha-21, 81(7), 36-39.

Pettit, G. S., Bates, J. E., \& Dodge, K. A. (1997). Supportive parenting ecological context and children's adjustment: A seven-year longitudinal study. Child Development, 68, 908-923. https://doi.org/10.2307/1132041

Pollack, E. (2012). Differential budgeting per student in the Israeli educational system. Study no. 57. Jerusalem: Koret-Milken Institute.

Porter, A. C., \& Gamoran, A. (2002). Progress and challenges for large-scale studies. In A. C. Porter, \& A. Gamoran (Eds.), Methodological advances in cross-national surveys of educational achievement (pp. 3-23). Washington, DC: National Academy Press. Retrieved from https://www.nap.edu/read/10322/chapter/2

Ravitch, D. (2010). The death and life of the great American school system: How testing and choice are undermining education. New York: Basic Books.

Tamir, Y. (2015). Who's afraid of equality? Tel Aviv: Yediot Aharonoth - Sifrei Hemed.

Volansky, A. (1999). The dialectic of decentralization and the center. In E. Peled (Ed.), Fifty years of Israeli education (pp. 283-296). Jerusalem: Ministry of Education.

Yair, G., \& Inbar, D. (2006). Standards for achievements in education: Touchstones, milestones, or tripping stones? In D. Inbar (Ed.), Toward educational revolution? (pp. 122-145). Jerusalem: Van Leer Jerusalem 
Institute and Hakibbutz Hameuchad.

Yogev, A., Livneh, I., \& Feniger, Y. (2009). Singapore instead of Karkur? International test achievement and globalization of educational goals. Megamot, 46(3).

Zaslavsky, O. (2006). What is gained and what is lost by participation in international studies? Retrieved from https://storage.cet.ac.il/SharvitNew/Storage/504105/256638.ppt

Zohar, A. (2013). Grades are not everything: Toward the rehabilitation of the pedagogic discourse. Tel Aviv: Sifriat Poalim.

\section{Copyrights}

Copyright for this article is retained by the author(s), with first publication rights granted to the journal.

This is an open-access article distributed under the terms and conditions of the Creative Commons Attribution license (http://creativecommons.org/licenses/by/4.0/). 